\title{
ARQUEOLOGÍA, PATRIMONIO CULTURAL Y POBLACIONES ORIGINARIAS: REFLEXIONES DESDE EL DESIERTO DE ATACAMA
}

\author{
ARCHAEOLOGY, CULTURAL HERITAGE, AND NATIVE POPULATIONS: \\ REFLECTIONS FROM THE ATACAMA DESERT
}

\author{
Mauricio Uribe Rodríguez* y Leonor Adán Alfaro**
}

\begin{abstract}
Este artículo se enmarca en el debate de cómo las sociedades construyen y reconstruyen sus memorias históricas, relacionado hoy en día con el concepto de "patrimonio cultural" y "procesos de etnogénesis" particularmente en naciones tercermundistas como Chile. Con este propósito, comenzamos aludiendo a nuestra experiencia científica y profesional en comunidades indígenas y locales del Desierto de Atacama, para enmarcarnos luego dentro de las reflexiones de la arqueología post-procesual o post-moderna y latinoamericana al respecto, insertándonos finalmente en la contingencia cultural específica del Estado chileno frente a este tema. Como resultado de este recorrido teórico, invitamos a la comunidad arqueológica a tomar una posición sobre el papel de la ciencia y, en particular, de nuestra disciplina dentro de la sociedad.
\end{abstract}

Palabras claves: Arqueología y sociedad, comunidades indígenas y locales, patrimonio cultural, desierto de Atacama.

This paper addresses the debate on how societies construct and reconstruct their historic memories, related today with the concepts of "cultural heritage" and "ethnogenesis processes" particularly in Third World nations like Chile. With these ideas, we begin describing our own scientific and professional experience with indigenous and local communities from the Atacama Desert. We situate ourselves in the post-processual or post-modern Latin American reflections on the subject, and we discuss the particular cultural contingency of the Chilean State regarding to these issues. As a result, we invite the archaeological community to take position concerning the role of science and, particularly, of our discipline in society.

Key words: Archaeology and society, indigenous and local communities, cultural heritage, Atacama desert.

En la parte mía como presidente del pueblo de Caspana, voy a agradecer..., que ellos por lo menos nos han tomado en cuenta a nosotros como comunidad. Llegaron a Caspana y ellos hicieron el trabajo no como ellos querían; ellos fueron respetuosos con nosotros y nos pidieron permiso para poder hacer esto, y a la vez nos pidieron que nosotros estuviéramos con ustedes... y así nosotros aprendimos algo, no voy a decir que aprendí mucho... Uno ve, como ser nosotros ahora en Caspana, que algunas partes en realidad, yo siendo de allá propio ni siquiera sabía. Entonces yo lo encuentro muy maravilloso que ustedes me hayan dado una oportunidad para hacer un alumbramiento de qué cosas hay dentro del pueblo de nosotros. Ahora yo estoy muy contento... (Juan
Anza, presidente de la Comunidad Indígena de Caspana, 1999).

...quiero decirles algo referente a lo que por lo menos compartí con ustedes... Para mí ha sido una cosa tan valiosa para poder decirles de cada uno de ustedes... de las cosas de las cuales yo especialmente aprendí de ustedes... conocí también los sitios que tal vez de repente, les contaba, no conocía, qué es lo que significaban y qué contenían los sitios arqueológicos, entonces para mí es una satisfacción y un honor y un orgullo, a la vez, haber conocido todas estas cosas. Y la manera de compartir de cada uno, sus personas, y también... tomar en cuenta en primer lugar a la comunidad de Caspana. Nosotros de alguna manera como ustedes lo obser-

* Departamento de Antropología, Facultad de Ciencias Sociales, Universidad de Chile. Ignacio Carrera Pinto 1045, Ñuñoa, Santiago.mur@uchile.cl; mur_cl@yahoo.com

** Dirección Museológica, Universidad Austral de Chile. Museo Histórico de Mauricio van de Maele, Isla Teja, Valdivia. ladan@uach.cl 
van en un punto de vista, somos dirigentes a los cuales debemos velar por nuestro pueblo y por nuestra comunidad. Entonces nosotros para poder llevar también de parte de ustedes el conocimiento a nuestra comunidad... de darle a conocer lo que hemos aprendido de ustedes y lo que ustedes nos han enseñado, ya sea tanto en los mismos sitios..., la discusión que ustedes tuvieron dentro de cada uno como profesores o qué sé yo, lo comparten, lo discuten de una manera tan clara para poder corregirse ambos, y saber ambos lo que a cada uno le pertenece y dónde les corresponde. Eso para mí me voy a ir bien conforme y contento y agradecido a la vez, y espero que no sea ni la última ni la primera (Bernardino Colamar, Secretario de la Comunidad Indígena de Caspana, 1999) ${ }^{1}$.

Consecuente con estas palabras, este trabajo intenta reflexionar en torno al debate del cómo las sociedades construyen y reconstruyen sus "memorias históricas" (Adán et al. 2001), relacionado hoy en día con el concepto de patrimonio cultural y, en particular, con el quehacer científico y social de la arqueología.

En este sentido, se propone una evaluación sobre el papel de la arqueología con relación al manejo de este patrimonio, en términos de la práctica y ética vinculadas con el desarrollo local y fenómenos de etnogénesis que, en nuestro caso, Chile se encuentra experimentando. Basándonos en nuestra dinámica laboral referida a la investigación científica, vinculada con museos e inserta en territorios con población originaria, planteamos la necesidad de singularizar y converger en una perspectiva patrimonial de quienes trabajan con los recursos arqueológicos del país. Esto significa que a través del reconocimiento de los múltiples interesados en ello, debido a las nada fútiles implicaciones culturales, sociales, políticas y económicas del pasado, se generen estrategias para una mejor valoración y proyección a futuro de dicho patrimonio.

Para tales efectos, a partir de nuestras experiencias de trabajo en Caspana, Quillagua y San Pedro de Atacama donde como arqueólogos no sólo nos enfrentamos al problema del entendimiento de los restos del pasado, sino también a las poblaciones locales que conviven, significan y valoran esos restos, nos sentimos con el deber y obligación de establecer un puente entre la arqueología, su conocimiento y las poblaciones que se encuentran vinculadas al pasado. En suma, se trata de confluir en una concepción de patrimonio que enfatice la participación colectiva de los recursos culturales.

\section{Arqueología, Prehistoria y Etnicidad en el Desierto de Atacama}

A partir de un análisis integral y comparativo de sitios y colecciones arqueológicas del Desierto de Atacama, intentamos explicarnos un hiato dejado por el desigual desarrollo de las investigaciones en San Pedro y el río Loa, impidiendo una comprensión más cabal de lo que hoy se denomina y reconoce incluso legalmente como Cultura Atacameña (Uribe et al. 2000).

En términos estrictamente arqueológicos, dentro de la secuencia cultural de la región se reconoce que a partir del Período Intermedio Tardío o de Desarrollo Regional (950 a 1.450 d.C.) se formaron las entidades de Atacama que tuvieron contacto con los españoles y que anteriormente habían sido conquistadas por el Inka (1.450-1.536 d.C.). A partir del 950 d.C. se aprecian transformaciones materiales que "rompen" con el período anterior como lo demuestran las evidencias de localidades como Yaye y Sólor en San Pedro de Atacama. Del mismo modo, se observa un momento posterior a Sólor e inmediatamente preincaico durante el cual aparecerían ciertas influencias altiplánicas detectadas en el Loa (p.e., Toconce y Turi), al interior de una homogeneidad material supuestamente representada por la "cerámica roja" como principal indicador del período. Como resultado del contacto anterior, esta nueva expresión de lo atacameño se extendería por las cuencas del Loa y el Salar de Atacama, posiblemente asociada a la expansión de poblaciones que construyeron numerosas aldeas y andenerías a lo largo de ellas (Uribe et al. 2002).

Por lo tanto, lo que hoy se denomina "atacameño" aparece ante la arqueología como el producto de múltiples y diversas poblaciones y sus cambios en el tiempo, sin configurar un grupo espacial ni culturalmente centralizado en el Salar, tal cual lo sugieren los documentos españoles y la misma etnografía (Castro 1997; Castro y Martínez 1996; Martínez 1997; Uribe et al. 2000 y 2002). No obstante, a partir de los datos materiales de este proceso, persisten las preguntas respecto a la existencia o no de una "unidad cultural atacameña", 
puesto que ha sido un tema no concluido por la investigación antropológica y tampoco por la memoria histórica de las propias comunidades indígenas de la región.

A esto se suma en la actualidad que nos enfrentamos a una situación nacional de reconocimiento y unificación étnica dirigida por el Estado, motivando a estas comunidades indígenas del Loa y San Pedro a declararse legalmente "atacameños", reconociéndose como un solo pueblo a pesar que la arqueología propone un origen mucho más diverso y complejo.

Por un lado, entonces, a nuestros ojos se hacía necesario evaluar estas situaciones sobre todo en San Pedro, que habiendo sido la principal fuente para la reconstrucción del pasado o "prehistoria" de Atacama, presentaba una serie de problemas arqueológicos en lo relativo a muestras, artefactos, contextos y cronología, los que habían sido mínimamente considerados en relación con los avances en el resto de la región. Por otro, sabíamos que la arqueología no podía basarse sólo en la información funeraria o cerámica para hacer prehistoria como había sido en este caso (p.ej. Le Paige 1964), ya que esos restos por separado constituyen una dimensión muy parcial de la vida en el pasado. Y, porque la arqueología tampoco podía negarse a su contexto histórico y social correspondiente al ejercicio de la disciplina en un territorio con poblaciones indígenas y donde, por lo tanto, el pasado sigue vivo.

En el marco de estos problemas surgió, en consecuencia, nuestra necesidad de sumergirnos en la reflexión teórica que al respecto la misma arqueología ha desarrollado en su seno, así como definir nuestra propia posición, intentando responder los cuestionamientos que se le hacen a la disciplina frente a estos temas.

\section{Ciencia, Pasado y Etnicidad}

Siguiendo a arqueólogos del primer mundo (Preucel y Hodder 1996), la contribución de la antropología al debate postmoderno ha sido la teorización autocrítica sobre la identidad cultural. De tal manera, que esta preocupación se ha extendido a cómo la misma antropología crea su sujeto y objeto de estudio, vale decir, cómo es concebido el "otro".

Lo anterior se remonta obviamente al origen colonial de la disciplina y a su creciente poder para construir sociedades a partir de la valorización de "lo primitivo", hasta hoy, cuando se utiliza el concepto de "tiempo" como categoría para diferenciar a las poblaciones indígenas de la occidental, y definir el valor de la producción cultural. En este sentido, el "otro" no sólo refiere a lo no-occidental, a lo menos desarrollado o a los indígenas, sino que también a la manera de construir la cultura occidental y su pasado como imágenes inversas o negativas de Occidente. Consecuentemente con esta cultura dominante, tal construcción sería coincidente con los intereses económicos y políticos de ésta (p.e. desarrollo versus subdesarrollo). Así, el "otro" es visto como un residuo del pasado, parado en el tiempo, mientras que nosotros somos un presente en movimiento. Sin duda, esto genera una actitud hacia las sociedades "menos desarrolladas" que permite negarles su identidad y homogeneizarlas, ubicándolas fuera de los derechos de la sociedad blanca. Por lo mismo, esta situación no sólo se refiere a "el otro" indígena, sino que se amplía a los géneros, las razas y las clases sociales, puesto que es producto de la historia y dinámica capitalista de Occidente (Preucel y Hodder 1996).

Como parte de esta historia, de acuerdo a los mismos autores, la arqueología occidental ha asumido igual actitud respecto a la construcción de "el otro". Desde el siglo XX la disciplina ha estado íntimamente conectada a una visión científica, objetiva y distante del pasado, la que fue impulsada a partir del siglo XIX por la idea de progreso, atribuyendo a lo "primitivo" el carácter de pasado estático. Por otro lado, el Romanticismo de esa misma época añadió el ideal de un pasado o futuro mejor de acuerdo al consumo de un mundo material mejor, en especial de aquellos objetos exóticos como los antiguos (en gran medida impulsando el consumismo fetichista de hoy en día). Todo esto habría configurado una sensibilidad nueva, un sentido particular de humanismo y solidaridad hacia el "desposeído", haciendo "más sensible" a la gente con relación a aspectos como el pasado, concibiéndolos como sin historia.

Con esta concepción el pasado fue separado de lo vivo y se "mató", se lo convirtió en algo extraño y la gente fue alienada de la historia, prohibiéndose sus individualidades. Siguiendo a Foucault (citado por Preucel y Hodder 1996), el pasado fue científicamente limpiado o "sanitizado". Aunque mucha gente, poblaciones y sociedades se 
mantuvieron junto a su pasado (incluidos los pueblos indígenas y también los coleccionistas), la profesionalización de la arqueología "disciplinó" la experiencia individual y grupal dentro de un pasado objetivo y despersonalizado. Lo anterior, más aún, se hizo evidente en el control que en la actualidad ejerce el Estado sobre la arqueología y los "monumentos públicos", y por medio de este "patrimonio" sobre la sociedad. De esta manera se recrea en lo social la diferencia entre un pasado vivo y otro muerto, de acuerdo a una racionalidad necesaria para adaptar, manipular y finalmente dominar a la naturaleza y al hombre, que no es sino la racionalidad del discurso científico occidental y la cultura dominante. En definitiva, aunque muy artificial y afecta a discusión, ha surgido entre nosotros una idea de que el pasado está muerto en oposición a un pasado vivo de los indígenas. Como asimismo, el pasado histórico estaría vivo a diferencia del prehistórico, en tanto se reconoce como válido el registro escrito, condenando a ciertos grupos a habitar en la prehistoria. En cierto sentido, los individuos prehistóricos se hallan doblemente muertos, sin vida ni historia.

Esta concepción del pasado y lo no-occidental manejado y creado por la arqueología, entra en conflicto con nuevos acercamientos interpretativos y fenomenológicos, asociados a nuevas formas de escritura o narrativa (Preucel y Hodder 1996). Pues, la racionalidad de la generalidad de la gente permite percibir que ésta no es la única visión sobre el pasado y que no es sólo el producto de Occidente; hay muchas maneras de concebirlo pues las otras sociedades también tienen una historia anterior. La arqueología, tal cual tiende a desarrollarse hoy, es usada o ejercida alienando el pasado como una representación objetiva, un "registro". Por esta razón, muchas poblaciones indígenas rechazan esta oposición entre pasado y presente. Para muchos de ellos, pasado y presente se construyen mutuamente, día a día, por lo que el tiempo no es lineal ni progresivo, sino cíclico e inmanente. De este modo, los sitios arqueológicos no están muertos ni son inertes. De hecho, en América y otras colonias, los invasores reconocieron esto y lo recategorizaron en términos cristianos, adscribiéndolos a la acción del "demonio". Pero ahora, la tradición oral y los mitos, que son las formas de conocimiento de ese pasado, son relegados a discursos marginales o a "materiales de estudio".
Sin embargo, hay coincidencia entre las perspectivas arqueológicas interpretativas y críticas con las percepciones indígenas sobre un pasado vivo, a pesar de los diferentes lenguajes y narrativas de unos y otros. Incluso, como respuesta a ello, algunos grupos se han unido formando organizaciones que enfrentan y/o incorporan la arqueología como parte de sus reivindicaciones (Adán et al. 2001). Y, como ésta permite diferentes lecturas e interpretaciones, en cuestiones de desarrollo, derechos de tierras y manejo de recursos culturales en situaciones occidentales, también muchos arqueólogos se han visto involucrados hablando en defensa y protección de tales temas. Por lo tanto, una solución al problema de las perspectivas indígenas y científicas del pasado, parece tener respuesta en el diálogo de los involucrados. Para esto, hay varios ejemplos como los de Norteamérica y Australia, especialmente en cuanto a repatriación y reentierro (Preucel y Hodder 1996).

Frente a acciones como éstas las predicciones de las comunidades académicas eran que los museos quedarían vacíos y los antropólogos perderían su objeto de estudio. Sin embargo, las peticiones han procedido de manera cauta por parte de las poblaciones indígenas, porque claramente existen problemas prácticos para ellos como el manejo de enormes volúmenes de material; al mismo tiempo que falta capacidad para realizar la reincorporación de los mismos siguiendo las tradiciones. Paralelamente, esto ha servido para renovar el interés por la cultura y el lenguaje, generándose un nuevo caudal de investigaciones e información y no una pérdida de ellas. Sin duda, esto es coincidente con el debate en la misma etnografía sobre la incorporación de las "otras" voces. Por lo mismo, estas voces pueden hablar y ser escuchadas a través del diálogo con los expertos científicos.

En cualquier caso, retomando a Habermas, Preucel y Hodder (1996) plantean que este diálogo debe ser estructurado creando condiciones ideales para que cada segmento participe con iguales posibilidades en la construcción de un consenso, consintiendo que el lenguaje se desarrolle como discurso sincero, comprensible y reivindicativo. No obstante, dicho diálogo es atacado por el mismo contexto histórico poniendo en conflicto ambas visiones del pasado. Es decir, las ideologías siguen actuando sobre el uso o concepción del pasado; por lo tanto, persiste el problema de cómo redefinir la relación entre el sistema global y el mundo indíge- 
na, permitiendo que las estructuras de este último puedan participar y mantenerse fuertes para resistir al mismo sistema. De hecho, el diálogo es a menudo desbalanceado a favor del poder dominante, confundiendo a los "aliados y enemigos" debido al ambiente confrontacional donde es ubicado este debate, ya que en general para ello se utiliza nuestro lenguaje, especialmente legalista, y no el del "otro" (aparte que el lenguaje escrito no es el único ni neutro).

El diálogo, entonces, debería ser posible solamente en aquellos términos aceptados por ambas partes, lo que no implica necesariamente una preparación de los indígenas en la ciencia "blanca", pues hay grupos que no la reconocen y, más aún, la rechazan, negándose posibilidades de negociación y/o compromiso. Una solución parece ser crear las propias formas de arqueología y ciencia, pero esta es una cuestión que otra vez complica la situación debido a las implicancias que tiene el cómo se "escribe" el pasado. El problema es, entonces, cómo realmente se toman en serio o en cuenta estas perspectivas nuevas de la ciencia y de "los otros", es decir, cómo se crea la idea de que el pasado está vivo cuando los "huesos" y objetos de los ancestros son los medios y mediadores del debate.

En suma, coincidimos con Preucel y Hodder (1996) que el concepto de "el otro" no sólo se refiere a la diferencia y diversidad, sino también a la idea de identidad occidental en tanto ésta se construye por referencia a la diferencia. Lo "otro" es simplemente lo opuesto al "uno mismo". Pero más allá del discurso postmoderno, la respuesta de los grupos indígenas es que ese discurso los sitúa en posiciones subordinadas, un "otro" abstracto y deshumanizado. Lo que rechazan, en definitiva, es ser definidos en términos negativos. Su propia historia y en sus propios términos debe ser considerada e incluida en el diálogo social, para también comprender las diferentes identidades a través de un proceso de negociación y discusión. El pasado, por lo tanto, no tiene que ser diferente a ellos, sino parte integral de los mismos, si no se trata sólo de seguir generando "otros" como fragmentos o imperfectos reflejos de nosotros mismos, lo cual es inadecuado e inhumano, pues aliena el pasado a los pueblos originarios, a los otros sexos o a las otras clases.

Por consiguiente, lo importante es comprender los diferentes contextos históricos que dieron origen a las diferentes narrativas, pues no hay un "uni-verso", sino "multi-versos", con lo que paralelamente se enriquece el pasado. Esto se traduce en beneficio para ambas partes, sobre todo en lo que se refiere a la identidad cultural, pues se abre una posibilidad de otras clases de arqueología: para y por los indígenas, para y por las mujeres y los marginados.

La respuesta profesional ha sido resistirse al pluralismo, argumentando que encubre un relativismo, impidiendo evaluar las interpretaciones. Pero, hoy es claro que todas las interpretaciones no son igualmente válidas, hay guías y fundamentos que permiten argumentar cuáles son mejores que otras de acuerdo a sus propósitos específicos y particulares historias, para lo cual debe promoverse la conciencia, el compromiso, el diálogo y la crítica.

\section{Reflexiones Latinoamericanas y Compromiso Social}

En este contexto no podemos pretender que nuestro quehacer en Sudamérica y Chile sea algo accidental o casual. Siguiendo a Trigger, Albarracin-Jordan (1997) plantea que el intervencionismo político y económico de los Estados Unidos a escala global después de la Segunda Guerra Mundial, alimentó el crecimiento de la corriente antihistórica en la arqueología, convirtiendo a la disciplina en antropología. Esto sucedía al amparo de argumentos como el "humanismo universal" con el objeto de disolver los programas nacionalistas, junto a la consolidación de su hegemonía mundial y la intervención del destino de los países, en especial tercermundistas y latinoamericanos en particular, donde el interés comunista también era inminente.

De este modo, en los países sudamericanos se promovió que la metodología importada era el mejor camino hacia el conocimiento del pasado prehispánico. En ese alineamiento se desarrollaron categorías temporales como los "horizontes" y "períodos", mientras que el eje espacial se dividió en áreas "nucleares" y "periféricas". La noción de "colapso", a su vez, engendró argumentos de carácter catastrófico como si Tiwanaku y los Inkas hubieran sido creaciones súbitas, dejando los períodos de "desarrollo regional" como fases radicalmente distintas de construcción social (Albarracin-Jordan 1997). En cierto sentido, el devenir 
social de los pueblos precolombinos se acomodó al modelo "universal".

Una de las reacciones propiamente sudamericana a esto fue la formación de la "arqueología social" en Perú hacia 1970, a partir de la cual se planteaba que la disciplina debía reconstruir el desarrollo de las sociedades antiguas hasta su unión histórica con las sociedades del presente. Dentro de esta corriente, el proceso no se concibe acumulativo sino que siendo creado, recreado, transformado y proyectado hacia el futuro; no existiendo discontinuidad entre el estudio del presente y el pasado (Lumbreras 1981). Al contrario, se propugnaba que la división entre "prehistoria", "historia" y "modernidad" tenía un tinte político y no una base teórica o metodológica, pues cumplía, por lo tanto, con determinados intereses de grupo. De este modo, la "arqueología social" intentaba llegar al público rompiendo con los parámetros exclusivos del academicismo y los profesionales que mistificaban la naturaleza de la disciplina. Sin embargo, en la actualidad el monopolio intelectual ejercido por los países desarrollados en Sudamérica ha hecho que el discurso arqueológico haya cedido a favor de las innovaciones foráneas, fortaleciendo la creación de determinadas imágenes del pasado prehispánico, las que son objetos de pugna por prestigio y poder en los círculos académicos norteamericanos y europeos (Albarracin-Jordan 1997).

Así, hoy las diversas formas de arqueología resultan del debate anglonorteamericano entre el modernismo y el postmodernismo, el neoevolucionismo y el relativismo, el positivismo y el simbolismo, cuyos temas y metodologías se nutren del pasado tercermundista. Por lo tanto, la historia misma de la arqueología demuestra que el conocimiento no es absoluto y que el contexto histórico como el ejercicio de la profesión, producen un condicionamiento primordial sobre él. Detrás de la jerga científica se han metamorfoseado poderosas fuerzas ideológicas, puesto que los programas de investigación responden a los intereses de las grandes hegemonías políticas del mundo, a las cuales se ajustan las políticas estatales nacionales, sobre todo de los países del mundo subdesarrollado. Y, cuya praxis se caracteriza por el cuasi hurto de la información, la marginación de la participación local, la despreocupación por la realidad económica y política de las poblaciones originales o indígenas, así como por la total ausencia de com- promiso del científico con ellas (Albarracin-Jordan 1997).

Si lo pensamos bien, entonces, la realidad de Chile y el ejercicio de la arqueología no resultan ser tan distintos, menos aún en el actual contexto político nacional e internacional. Hoy, el tercer gobierno "concertacionista" del período democrático iniciado en 1990, es uno de los promotores más importantes de una política cultural de toda la historia nacional:

El gobierno actual ha colocado a la cultura en el centro de sus preocupaciones (...) Atendidos los avances que tuvimos como país durante la década pasada, de lo que se trata hoy no es de hacer un brusco giro en el camino que veníamos transitando, sino mantenernos en la ruta, apurar el tranco, y, sobre todo, proponernos metas más ambiciosas de las que pudimos alcanzar la década pasada. Metas más ambiciosas que nos sentimos ahora capaces de alcanzar porque antes fuimos también capaces de lograr metas previas que parecían tan difíciles como las que ahora nos proponemos (...) nuestro objetivo final es alcanzar buenos niveles de un desarrollo que se mide no sólo por indicadores económicos, sino por criterios que dependen también de la satisfacción de esas necesidades y expectativas más intangibles y profundas de la persona humana, que tiene que ver con la creación, acceso y goce de los bienes simbólicos (Lagos 2000).

De este modo, a la cultura se le da un carácter patrimonial, de herencia, pues se la relaciona con el sello distintivo de un país, con el espíritu más permanente que lo anima y vivifica, con la identidad que ese país tiene y que lo caracteriza y a la vez lo diferencia de otras naciones. Surge así un concepto de identidad nacional no indeleble, pues no acompaña por siempre a un país, ya que se trata de un proceso donde se combinan estabilidad y cambio. Por lo tanto, "El concepto de identidad nacional no tiene el rasgo esencialista que le conferían visiones estáticas ya superadas, y se convierte hoy en una verdadera categoría de movimiento en la que conviven tanto la tradición como la novedad, lo propio y lo ajeno, lo único y lo diverso..." (Lagos 2000). 
Lo anterior, en este sentido, se relaciona con el fenómeno de la globalización y de la inserción de Chile en el concierto internacional, pues:

lo que la globalización demanda hoy a los distintos países no es la renuncia a las lealtades nacionales a favor de lealtades más ampliamente planetarias, sino una ampliación de las lealtades nacionales a fin de dar cabida a aquellas que es preciso reconocer a nivel continental y mundial (...) la globalización será un proceso que acabará produciendo un resultado más rico y diverso que el que podría producir la simple hegemonía de una determinada cultura nacional a escala mundial. La identidad cultural del país no es una identidad de defensa o de resistencia, sino una de afirmación y proyecto, de manera que la inserción de Chile en un mundo que se globaliza no supone ni la renuncia a nuestros sueños ni la cancelación de nuestra memoria como país (Lagos 2000).

En consecuencia, esta política se propone:

conseguir la cooperación que en el orden cultural debe existir entre la libertad de las personas, la existencia de un mercado en este campo y la presencia que en ese mismo campo corresponde al Estado, de modo de comprender que ninguno de esos tres factores puede ser invocado para prescindir de uno u otros de ellos, y de comprender, asimismo, que sin la presencia del Estado hay cultura, mas no desarrollo cultural (Lagos 2000).

Sin duda, frente a este programa de Estado hay temas que preocupan debido a las múltiples lecturas y cierta ingenuidad que deja traslucir el discurso político, y que ameritan reflexión y discusión. En especial, entre muchos otros aspectos, destaca el valor dado a la cultura como vía para aprovechar los avances logrados respecto al pasado, satisfacer las necesidades espirituales o simbólicas y la incorporación de Chile a la globalización (p.e. el mercado internacional). En definitiva, sin otorgarle todavía valores morales positivos o negativos, la cultura hoy (como antes) está cumpliendo un rol ideológico en términos de su manejo político.
Ante ello, los profesionales y pensadores de la cultura deberíamos tener una opinión y postura que quizás ya es tiempo de construir. En particular, para los arqueólogos esto resulta trascendental, puesto que el patrimonio cultural que forma nuestra "identidad nacional" se concibe como herencia, una herencia recibida desde el pasado remoto, el cual en gran medida ha sido y está siendo reconstruido por nuestra disciplina. Esto, a pesar que nuestro conocimiento apenas se haya integrado a las políticas de educación -cuestión que también habría que discutir. En este sentido, retomamos el papel activo que le cabe a la arqueología como ciencia social o la función social de ella, y no el de espectador aséptico de los fenómenos naturales y humanos. Esto se debe a que parte importante de nuestra identidad nacional ha negado y manipulado evidente y arbitrariamente el pasado prehispánico que es constituyente esencial del patrimonio cultural del país. Pero, hoy no se puede perder la oportunidad de intervenir en esas directrices, por cuanto existe un contexto histórico receptivo para repensar estos temas, así como para hacer explícitas las demandas respecto a ellos.

Frente a esta posición del Estado chileno, uno de los aspectos que queremos recalcar es la relación entre arqueología y poblaciones originarias en el proceso de conocimiento y reconstrucción del pasado, o sea en la investigación científica.

Coincidentemente, Carpio (1997) plantea que en la actualidad, ante las grandes agitaciones sociales, los países subdesarrollados que conforman América Latina buscan soluciones a las crisis internacionales que suelen originarse en el seno de las sociedades industrializadas, y que golpean sin misericordia a los países pobres. Dentro de la búsqueda de soluciones se plantea, como primer paso, la definición de una identidad nacional que permita desarrollarnos como naciones con valores auténticos. Pero, en este caso, libres del "monstruo" consumista y antivalorativo, orquestado desde fuera de nuestras fronteras, dirigido para manejar todo desarrollo autónomo y controlar la identidad de cada nación. Ya que, según su opinión, se contaría incluso con la participación de grupos hegemónicos locales que se apoderan de los recursos naturales y manipulan los valores culturales de los pueblos bajo su dominio (p.ej., el Estado y la empresa).

Dentro de los valores auténticos que ayudarían a alejarse del contexto anterior, Carpio propone que debemos recordar y promover que nuestros 
países estuvieron habitados por sociedades prehispánicas, cuyo desarrollo social y cultural se manifiesta aún hoy en día y se encuentra amalgamado en la dinámica del presente, representando gran parte de los valores culturales de cada nación. Por tales razones, la arqueología debería buscar la comprensión del presente, asignando al pasado el papel que le corresponde, apoyándose sobre bases teóricas sólidas, y con la capacidad -actuando desde una posición política definida- para señalar la manipulación de la cual son objeto las manifestaciones culturales del pasado por parte de grupos que en la actualidad, con el propósito de defender sus intereses particulares, pretenden crear falsos nacionalismos, desvirtuando, distorsionando y destruyendo el significado de estos valores (Carpio 1997).

\section{Hacia una Toma de Posición}

Coincidimos con Carpio, que la arqueología tiene un compromiso fuerte con la sociedad, sobre todo en Latinoamérica, en el sentido de dotar desde la perspectiva de su ciencia y objeto de estudio (los restos materiales), de un cuadro de procesos donde cada sociedad experimentó sus propias contradicciones que fueron el motor del desarrollo original de América, pero cuyos procesos fueron truncados y alterados con la llegada hispana.

Conscientes de esto último, no se puede pretender utilizar valores culturales del pasado, como en cierto modo lo hacen nuestros folclores, para identificar plenamente a naciones actuales pobres y dependientes. El papel del arqueólogo como científico social, por consiguiente, se encamina a la búsqueda de la información que le permita la comprensión coherente del comportamiento social y la historia que nos ha precedido, superando la idea de un pasado muerto e inerte. Sólo de esta manera la investigación arqueológica aportará con una pieza fundamental que servirá para comprender la dinámica del presente. Por lo tanto, solamente siguiendo paso a paso la conformación histórica de nuestras sociedades y asumiendo una actitud política definida y orientada al beneficio de los distintos componentes del grupo mayor (p.ej., clases, indígenas o sexos), generaremos las metodologías para que la arqueología y las demás ciencias sociales logren su cometido y a la vez se evite el mal uso y abuso de las manifestaciones culturales enmarcadas en cada una de nuestras naciones. De esta forma es que la arqueología tendrá un papel importante que jugar en el seno de la sociedad donde actúe, dejando así de trabajar aisladamente y alejada de la realidad (Carpio 1997).

Por estas razones queremos volver a nuestro problema inicial, vale decir, cómo nos planteamos en nuestra praxis frente a las propias contingencias históricas, particularmente a nuestra relación con las comunidades indígenas y locales de las cuencas del río Loa y el Salar de Atacama. Para ello compartimos, a partir del trabajo desarrollado en sus territorios y el diálogo con algunas de estas comunidades $^{2}$, nuestra percepción sobre la investigación arqueológica y una mejor comprensión de la construcción cultural.

De acuerdo a ese diálogo, uno de los temas cruciales en la actualidad es la necesidad de establecer relaciones más estrechas entre quienes trabajamos en investigación y las poblaciones locales, herederas o depositarias de este patrimonio cultural. En muchas partes de nuestro país, la arqueología debe responder -y responsabilizarse ante el punto de vista indígena- por una forma de practicar la disciplina que desarrollaron los primeros arqueólogos. Resulta difícil explicar que la arqueología no sólo excava cementerios, que investiga para resolver problemas y que es radicalmente diferente del trabajo de los buscadores de tesoros o saqueadores de tumbas, anticuarios y coleccionistas. Se suma a lo anterior, una cierta desidia de la arqueología y la investigación en general por promover y fomentar instancias de coordinación o encuentro con las comunidades locales o indígenas, como una forma de "evitar el conflicto" y ante situaciones conflictivas sólo "reaccionar". Lo anterior mantiene a la investigación en territorios con población indígena a una prudente distancia, o bien evita trabajar en ellas, como ocurre en la zona sur de Chile.

Obviamente, la tensión investigación del pasado-comunidades indígenas refleja a un nivel micro el conflicto Estado-Pueblos Originarios. Debido, por ejemplo, a que la mayor parte de las investigaciones son financiadas con aportes estatales (p.ej., Consejo Nacional de Ciencia y Tecnología o CONICYT), debiendo cumplir con ciertas exigencias y una determinada idea de ciencia positivista, que en nuestro caso imprime un enorme distanciamiento de las comunidades locales. A esto se suma la ausencia de una coordinación a nivel de instituciones del Estado que tienen relación con 
ciencia, pueblos indígenas y patrimonio, pues el Fondo Nacional para la Investigación Científica y Tecnológica de CONICYT (FONDECYT), no requiere del conocimiento, opinión ni menos aprobación de la comunidad o de la Corporación Nacional de Desarrollo Indígena (CONADI); mientras que el actual funcionamiento de entidades como el Consejo de Monumentos Nacionales, que regula la actividad e intervención sobre los restos arqueológicos pero también sobre el patrimonio cultural de Chile en general, se encuentra burocrática, económica y legalmente superado para enfrentar una tarea tan particular como ésta. Por último, en gran medida los fondos entregados para la ciencia sólo pueden ser empleados en investigación, por lo cual las labores de conservación, documentación, almacenaje y finalmente difusión, se constituyen más un lastre que un beneficio, en especial para las universidades y museos que deben recibir las colecciones arqueológicas o etnográficas.

$\mathrm{Al}$ contrario, creemos que estos proyectos deberían manejar un concepto más amplio e integrador de patrimonio, segregable sólo con fines operativos. Estrechamente relacionado con ello, se encuentra el hecho que el trabajo científico ha de fundamentarse en un proceso que permita la apropiación social y resignificación para la población local de sus recursos culturales. En otros términos, el patrimonio es una idea que contiene valor diferencial para científicos, conservadores y comunidades, como asimismo para los distintos segmentos de la sociedad nacional, donde se encuentran otras clases y sexos. Desde el punto de vista de las comunidades, al menos, nos ha quedado claro que la investigación y conservación de su patrimonio debe tener consecuencias sociales, económicas y políticas concretas, por lo cual el por qué estudiar y para qué conservar son temas que tienen muchas posibilidades y programas por implementar, pero deben comprender su propia visión del asunto. Por lo mismo, muchos proyectos deberían surgir o incorporar las iniciativas locales, ya que está sumamente probado que propuestas impuestas desde afuera tienen escaso impacto y proyección, e incluso pueden despertar resistencia, como por ejemplo hemos visto en Atacama. Frente a esto, sin embargo, y en ello los interlocutores indígenas han sido sumamente claros, el papel de quienes estamos en las ciudades, universidades, instituciones del Estado o privadas, debería ser el de facilitar el acceso, informa- ción y manejo de los recursos culturales para las comunidades, y no descansar en cierta forma de proteccionismo o romanticismo, que oculta una falta de interés hacia estos temas.

Bajo un marco como éste, creemos que la colaboración con las comunidades indígenas o locales donde trabajamos permite profundizar y perfeccionar su propio desarrollo, al mismo tiempo que retroalimenta la propia investigación científica. De hecho, en el desierto de Atacama esto es lo que han promovido ciertos equipos de investigación desde la década de 1970 en adelante, como el grupo Toconce -dirigido por Victoria Castro y Carlos Aldunate-, y del cual nos sentimos herederos. Gracias a ello, existe la posibilidad y el gran desafío de conciliar los intereses científicos y de las comunidades. Según estas experiencias, poco a poco tal oposición puede desdibujarse, por lo cual la investigación científica podría adquirir otros matices y dar lugar a diferentes procesos sociales en el cual la arqueología debería participar.

De este modo, la arqueología debe posicionarse en su contexto histórico, ya sea para seguir desarrollando su labor de la manera tradicional, o, incentivando otras arqueologías como la social, del género, etc., pero siempre en conciencia y alerta; puesto que, como hemos visto, el conocimiento del pasado tiene una clara función social en tanto forma parte de las ideologías que configuran nuestro mundo e identidad. Debemos desprendernos de la ingenuidad impuesta por la ciencia occidental y el capitalismo, y asumir que nuestro quehacer tiene efectos sociales importantes, que obviamente no tienen por qué caer en el paternalismo ni indigenismo igualmente ingenuos, ni tampoco dejar de hacer arqueología. Por el contrario, se trata de seguir haciendo ciencia pero en "conciencia", aceptando el diálogo y participación de los otros, así como siendo críticos al ámbito histórico específico. En definitiva, llamamos a estar atentos a las situaciones que estamos viviendo y tener opinión frente al público como, por ejemplo, apoyar o no la existencia de "una" cultura atacameña, las connotaciones políticas de la etnogénesis, exponer el carácter etnofóbico que muchas veces adquiere el mismo discurso indígena en Chile, integrar a otros actores sociales casi desconocidos en la construcción de la historia como el mestizo o las mujeres, o develar la carga ideológica que encierran los conceptos de pasado, identidad nacional y patrimonio cultural. Sin duda, en todo esto la arqueología tie- 
ne mucho que decir, puesto que, querámoslo o no, tiene un rol que cumplir y que hoy en día le está llamando a comprometerse. En particular, generar un discurso que supere las consecuencias de nuestra dicotomía entre pasado y presente, las mismas que siguen reproduciendo concepciones tan prejuiciosas como primitivo y moderno, historia y prehistoria, ciencia y mito, indios y blancos.

Agradecimientos: En primer lugar, éstos se dirigen a Patricia Ayala, Sergio Avendaño y Ulises Cárdenas como a través de ellos a toda la Comunidad Indígena de Ollagüe por habernos invitado a participar en su Encuentro patrimonial. Asimismo, agradecemos a todos aquellos que estuvieron y con quienes compartimos en este importantísimo evento que reunió a dirigentes indígenas, científicos, profesionales e interesados en el tema de ambos lados de los Andes. Por otra parte, nuestro trabajo no sería tal si no recordáramos a la Comunidad de Caspana como motor de estas ideas, lo que extendemos a todos los pueblos originarios y tradicionales del Loa y San Pedro de Atacama. En el mismo sentido, esto tampoco habría sido posible si no hubiésemos sido acogidos y formados por la particular sensibilidad de Victoria Castro R. Esta reflexión ha resultado del Proyecto Fondecyt 1000168 "Historia cultural y materialidad de los períodos Intermedio Tardío y Tardío de San Pedro de Atacama y su relación con la cuenca del río Loa".

\section{Referencias Citadas}

Adán, L., M. Uribe, M. Godoy, C. Jiménez y D. Salazar

2001 Uso del patrimonio cultural en la construcción de memorias e identidades históricas nacionales. Ponencia presentada en el IV Congreso Chileno de Antropología. http:/ /rehue.csociales.uchile.cl/antropologia/congreso/ s0614.html(enero 2002).

Albarracin-Jordan, J.

1997 Ciencia, arqueología y patrimonio. Humana 1(1): 41-50.

Carpio, E.

1997 Arqueología e identidad nacional. Humana 1(1): $37-40$.

Castro, V.

1997 Huacca Muchay. Evangelización y Religión Andina en Charcas, Atacama la Baja. Tesis para obtener el grado de Magíster en Etnohistoria, Facultad de Filosofía y Humanidades, Universidad de Chile, Santiago.

Castro, V. y J. L. Martínez

1996 Poblaciones indígenas de Atacama. En Culturas de Chile. Etnografía, editado por J. Hidalgo, V. Schiappacasse, H. Niemeyer, C. Aldunate y P. Mege, pp. 68-110. Editorial Andrés Bello, Santiago.

Lagos, R.

2000 Política Cultural del Gobierno del Presidente de la República Señor Ricardo Lagos Escobar. http://www. culturachile.cl/lib_docs/politica.doc (agosto 2002).
Le Paige, G.

1964 Los cementerios de la época agroalfarera en San Pedro de Atacama. Anales de la Universidad del Norte 3.

Lumbreras, L. G.

1981 La Arqueología como Ciencia Social. Ediciones PEISA, Lima.

Martínez, J. L.

1997 Pueblos del Chañar y del Algarrobo. Los Atacamas en el Siglo XVII. DIBAM, Santiago.

Preucel, R., y I. Hodder

1996 Constructing identities. En Contemporary Archaeology in Theory: A Reader, editado por R. Preucel y I. Hodder, pp. 601-614. Blackwell Publishers, Oxford.

Uribe, M., L. Adán y C. Agüero

2000 Arqueología de los períodos intermedio tardío y tardío de San Pedro de Atacama y su relación con la cuenca del río Loa. Ponencia presentada en XV Congreso Nacional de Arqueología Chilena, Arica.

Uribe, M., L. Adán y C. Agüero

2002 El dominio del Inka, identidad local y complejidad social en las tierras altas del desierto de Atacama, Norte Grande de Chile (1.450-1.541 d.C.). Ponencia presentada en el IV Simposio Internacional de Arqueología PUCP, Lima.

\section{Notas}

1 Dedicatoria a la Memoria de don Julián Colamar. Al futuro del pueblo de Caspana, en Estudios Atacameños 18:5-6.

2 Encuentro "El Dominio Inka en las quebradas altas del Loa Superior: Un acercamiento al pensamiento político andino”, Proyecto Fondecyt 1970528, Instituto de Investigaciones Arqueológicas y Museo R. P. Gustavo Le Paige S. J., Fundación Andes, Caspana-San Pedro de Atacama, 1999. 